\title{
We are Still Learning About the Nature of Species and Their Evolutionary Relationships
}

Author(s): Peter J. Lockhart, Anthony W. D. Larkum, Matthias Becker, and David Penny

Source: Annals of the Missouri Botanical Garden, 100(1-2):6-13.

Published By: Missouri Botanical Garden

URL: http://www.bioone.org/doi/full/10.3417/2012084

BioOne (www.bioone.org) is a nonprofit, online aggregation of core research in the biological, ecological, and environmental sciences. BioOne provides a sustainable online platform for over 170 journals and books published by nonprofit societies, associations, museums, institutions, and presses.

Your use of this PDF, the BioOne Web site, and all posted and associated content indicates your acceptance of BioOne's Terms of Use, available at www.bioone.org/ page/terms_of_use.

Usage of BioOne content is strictly limited to personal, educational, and noncommercial use. Commercial inquiries or rights and permissions requests should be directed to the individual publisher as copyright holder. 


\title{
WE ARE STILL LEARNING \\ Peter J. Lockhart, ${ }^{2}$ Anthony W. D. Larkum, ${ }^{3}$ \\ ABOUT THE NATURE OF SPECIES Matthias Becker, ${ }^{2}$ and David Penny ${ }^{2}$ \\ AND THEIR EVOLUTIONARY \\ RELATIONSHIPS ${ }^{1}$
}

\begin{abstract}
Early evolutionary thinkers proposed relatively simple models to describe processes of evolution, and these are the basis of evolutionary models still used today. Recent research has since shown that evolutionary relationships among plants can be complex and difficult to reconstruct even from molecular data. In plants there is a continuum of processes, ranging from reticulate relationships within a sexually reproducing population, incomplete lineage sorting and hybridization between recently diverged species, allopolyploidy between more distantly related species, to symbioses and endosymbiosis. These aspects of plant biology can create practical problems for interpreting bifurcating gene trees and identifying species. The promise of "omics" is that it will provide data and analyses to improve our understanding of the nature of species and their phylogenetic relationships. We highlight the importance of distinguishing evolutionary processes and evolutionary models, and stress that improving the understanding of micro-evolutionary processes is necessary to inform current debate on whether or not to accept paraphyletic species.
\end{abstract}

Key words: Evolution, genomics, hybridization, paraphyly, species concepts.

Most researchers agree that practicality, usefulness, and predictability are important considerations for whether or not paraphyletic species should be recognized in taxonomy. However, while some authors suggest that biological classification should capture more evolutionary information (Hörandl \& Stuessy, 2010), others question whether the acceptance of paraphyletic species as units for classification better reflects processes of evolution and patterns of biological diversity (Schmidt-Lebuhn, 2011). A central question to resolve is: What can phylogenetic analyses tell us about the nature of species and evolutionary relationships? This question, and the debate over recognition of paraphyletic species, is rapidly being informed by genome science. Its promise is that it has the potential to tell us much about paraphyly, polyphyly, repeatability of evolution, and the spatial and temporal extent of interspecific gene flow. This information is important for understanding the nature of species and the suitability of gene tree and species tree methods for reconstructing evolutionary histories and developing robust taxonomies.

\section{The Notion of Species Used When Building Species Trees}

It has been said that "all that is empirically demonstrable are species-they must exist because we observe discontinuities between groups of organisms (Coyne \& Orr, 2004) — and clades, which are the inevitable consequence of common ancestry and speciation processes (Wiley, 2009), and are recognizable from their synapomorphies" (Schmidt-Lebuhn, 2011: 178).

The idea of "species" as a fundamental unit certainly predates Darwin and Wallace. Earlier concepts were not of species but were "forms" and "kinds" of plants and animals that could even appear spontaneously (as mentioned in the King James Version of the Bible published in 1611). However, during the 17th century the concepts of "species" and "genera" developed, and as far as we can tell, John Ray, in his Natural Theology book of 1691, was one of the earliest writers to discuss species in a modern sense (Raven, 1986). As pointed out by Mayr (1968: 165), Ray, in discussing criteria that identify species, considered it essential that species "spring from the seed of one and the same ..." This is an idea in essence equivalent to the biological species concept that would obtain its popular form 250 years later. Ray gathered plants from various places in England and grew them all in his own garden, thus, separating inherited and environmental effects. He concluded that "varieties" could come from the same parent plant and were members of the same species.

\footnotetext{
${ }^{1}$ We thank Trish McLenachan, Elvira Hörandl, David Bryant, Simon Joly, and two anonymous reviewers for helpful comments on our manuscript. We gratefully acknowledge funding from the New Zealand Marsden Fund and Massey University.

${ }^{2}$ Institute of Fundamental Sciences, Massey University, Palmerston North, 4442, New Zealand. P.J.Lockhart@ massey.ac.nz.

${ }^{3}$ University of Technology, Sydney, 15 Broadway, Ultimo NSW 2007, Australia.

doi: $10.3417 / 2012084$
} 
These early concepts of having "members" of a set (species) within larger sets (genus) were also used by other authors at the time to describe different kinds of crystal structures (species) in rock. In doing so, there was no suggestion or implication that species, whether plants, animals, or rocks, could ever change or merge into other species over time. This way of thinking was formalized in the mid-18th century when Linnaeus (1736) codified a system that was universally adopted for classifying animals and plants, and which had as its basic unit the species. Much later, when championing the biological species concept, Mayr also emphasized the discrete and distinct nature of species-a consequence of individuals from one species being reproductively isolated from individuals of another species (Mayr, 1963; Donoghue, 1985). Although some botanists have abandoned the biological species concept when discussing plant diversity, it is Mayr's way of thinking about species that has most influenced the development of modern methods for species delimitation (Fujita et al., 2012) and current methods for species tree reconstruction. An important question is whether such approaches are generally appropriate in plant systematics.

\section{Adoption of a Treelike Model for Evolution}

The developers of species tree methodology have taken some ideas from Darwin but not others. Darwin was convinced of descent by modification and at least partly by the treelike nature of evolutionary processes (Penny, 2011). He recognized morphological discontinuities as the result of the process of divergence and extinction (Mallet, 2008a). One could assume that it was a species tree that he had in mind when he first sketched a sticklike tree figure in his now famous notebook (see <http://darwin-online.org.uk/>), but it could also have been populations or varieties. It is not clear what he meant in terms of evolutionary relationships and the biological processes that were depicted. Both Darwin and Wallace had a notion for species trees and models for describing evolutionary relationships between species. In his 1855 paper, Wallace referred to "trees" and "evolution" in at least two places. In the first, he says "Much discussion has of late years taken place on the question, whether the succession of life upon the globe has been from a lower to a higher degree of organization? (p. 191)... and the progression from Fishes to Reptiles and Mammalia, and also from the lower mammals to the higher, is indisputable In the second passage that immediately follows, he says, "returning to the analogy of a branching tree, as best mode of representing the natural arrangement of species and their successive creation, let us suppose that at an early geological epoch any group (say a class of Mollusca) has attained to great richness of species and high organization. Now let this great branch of allied species by geological mutations, be completely or partially destroyed. Subsequently a new branch springs from the same trunk, that is to say, new species are successively created, having their antitypes the same lower organised species which had served as the antitypes for the former group, but which have survived the modified conditions, which destroyed it. ..." It is clear that Wallace had the idea of a phylogenetic tree (and Darwin noted that he "uses my simile of tree" on his copy of Wallace's paper, probably annotated about 1856-1857), even though Wallace had not fleshed out this concept in detail (Brooks, 1984).

In On the Origin of Species, Darwin (1859) goes over much of the same ground as Wallace. One might think that it is a species tree, but he, too, does not detail the nature of this tree; the only tree figure in On the Origin of Species is one that Darwin largely moved from his unpublished "Big Book" (Stauffer, 1975), where Darwin had another purpose in mind for this tree. There it was bound up with his somewhat undefined concept of "The Principle of Divergence." Simply put, "The Principle of Divergence" is the outcome of the "Struggle for Existence" in terms of species (or as the full title to On the Origin of Species puts it "By Natural Selection or the Survival of Favoured Races in the Struggle for Life"). However, note that neither Wallace nor Darwin followed this through in a tree that mapped out how a species tree might look. Darwin's (non-binary) tree as first envisaged in the "Big Book" showed how populations, varieties, and species might change under competition and under the forces of extinction (not individually but over generations), and it was not concerned with a genealogy showing all species formations and losses. In On the Origin of Species, Darwin used much the same diagram to map how a group of related organisms (species or subspecies?) might change over time. However, in the diagram, Darwin did not define species. He was very careful not to do this, and he viewed the situation as being very plastic between races, species, and genera.

Perhaps, ironically, it is Darwin's treelike representation that is the evolutionary model adopted for reconstructing and visualizing evolutionary relationships, while at the same time he has been criticized for his concept of species (Mallet, 2008a). This duality also applies to recent species tree reconstruction methods, which assume an evolutionary treelike model but do not model gene flow between species. 


\section{Building Species Trees}

Recent years have seen exciting developments in methodology for reconstructing evolutionary relationships between species. In particular, based on the assumption that species comprise monophyletic assemblages of individuals, numerous new "multispecies coalescent" methods have been developed for inferring evolutionary relationships from nucleotide sequence data (Knowles, 2009; Kubatko et al., 2009; Liu et al., 2009; Heled \& Drummond, 2010; Fan \& Kubatko, 2011; Bryant et al., 2012). These methods assume a treelike model for evolution and accept that, while individual gene trees on occasion might indicate paraphyly, such gene trees have, nevertheless, evolved on an underlying species tree in which each species is genetically isolated; thus, individuals of each new species are monophyletic with respect to individuals of other species. Species tree building methods do not test whether or not this is an appropriate model for describing the evolutionary relationships among the taxa being studied.

Tests for inferring the evolutionary significance of observed patterns of monophyly among gene trees can be applied prior to species tree reconstruction and identification of reproductively isolated "species" based on minimum expectations for the extent of monophyly observed in analyses of independent genes (e.g., Rosenberg, 2007). Similarly, since the expected theoretical distribution of gene trees on a given species tree can be calculated (Degnan \& Salter, 2005), then given a large enough sample of independent gene trees, in principle it is possible to examine whether there is a good fit between the optimal species tree (representing the evolutionary model) and the observed gene trees (Fan \& Kubatko, 2011). In practice, this is not done. However, as we discuss below, it is possible to test whether or not gene trees have evolved under evolutionary models involving hybridization. In this case, if statistical evidence rejects a simpler evolutionary scenario, it is more difficult to reconstruct multi-species coalescent species trees.

Despite this concern, multi-species coalescent methodology has value for plant systematics because radiations have been important in the formation of many extant plant species (e.g., Martin et al., 2005; Winkworth et al., 2005; Linder, 2008; Pennington et al., 2010; Valente et al., 2010). Under such evolutionary scenarios, reconstructed gene trees are likely to contain short internal branches and long external branches. This is a situation in which phylogenetic accuracy can be low, particularly where there is substitution model misspecification (Hendy \& Penny, 1989; Shavit et al., 2007). Furthermore, even if accurately determined, gene trees can be discordant with the true underlying species tree. This is a theoretical expectation where ancestral population sizes of extinct species are relatively large and where times between diversification events are relatively small at the base of the species tree. Indeed, there are certain combinations of ancestral population sizes and divergence times where the majority of gene trees are expected to be incongruent with the species tree on which they have evolved (Degnan \& Rosenberg, 2009). For these reasons, the idea of a methodology for reconstructing species relationships that accounts for the problem of discordant and paraphyletic gene trees due to incomplete lineage sorting is very appealing. Thus, the hope is for more reliable phylogenetic inferences from multi-species coalescent methods that could be used by biologists to inform taxonomy.

The problem is that the multi-species coalescent models currently used for building species trees do not model gene flow between species, and for organisms that diverge with gene flow, it is unclear how effective the methodology is. In practice, too few empirical studies have been undertaken to yet know whether or not current implementations of multispecies coalescent tree methods provide a general and useful tool for plant systematics and taxonomy. One recent study examined six species of wild rice and noted extensive discordance of gene trees for these species. The authors reported more discordance than was expected under a coalescent model with no gene flow. Not surprisingly the authors found that a Bayesian species tree method (BEST) was unable to converge on the expected species tree topology (Cranston et al., 2009). Recent work has also used computer simulations to study the performance of the same BEST and the impact of horizontal gene transfer (as might occur through interspecific hybridization). In this case, it was found that when introgressed sequences were distributed asymmetrically between species (meaning a greater proportion of the genome of species A was present in species B than the genome of B was in species A), BEST also performed poorly (Chung \& Ané, 2011). Nevertheless, this is still not very much information to go on, and the disappointing result might reflect more the coalescent model used rather than the method itself. There are coalescent models that do not assume symmetric patterns of gene flow (e.g., such as that developed by Beerli \& Felsenstein, 2001), and while these are not yet implemented in building species trees, perhaps such models represent a useful direction for future research. 
Although hybridization between some species has gained only recent acceptance in the zoological research community (e.g., see discussions by Mallet, 2007, 2008b), almost 300 years of botanical investigation suggest its importance for understanding the nature of species and describing their relationships (e.g., Ehrendorfer, 1959; Stebbins, 1959; Arnold, 1997; Rieseberg, 1997). Recent work recognizes the occurrence of hybridization in both animal and plant species radiations (Herder et al., 2006; Mallet, 2007; Soltis \& Soltis, 2009; Stemshorn et al., 2011) and in evolutionary adaptation to environmental change (Hoffman \& Sgro, 2011). If hybridization is as common and evolutionarily significant as many researchers have now suggested, then multi-coalescent species tree methods in their current form might have limited applicability for reconstructing plant species relationships and informing debate on recognition of paraphyletic species.

\section{New Zealand Alpine Ranunculus}

Hybridization is regarded as a conspicuous feature of the New Zealand flora (Cockayne \& Allan, 1926). Within this flora, a group of 20 or so alpine Ranunculus species was described (Fisher, 1965; Webb et al., 1988; Heenan et al., 2006) as an adaptive radiation wherein convergent morphologies appeared in similar habitats across the New Zealand landscape. Phylogenetic analyses of nuclear ITS and chloroplast $y c f 1$ sequences from New Zealand alpine Ranunculus species reported in Lockhart et al. (2001) uncovered numerous examples of non-monophyletic relationships in reconstructed gene trees. Additional sequencing of the same loci has since identified further examples of non-monophyly. Figure 1 illustrates relationships inferred for species representing one of the two main breeding groups. It has been unclear to us how such patterns of non-monophyly should be interpreted. Different species from the same geographic regions have nuclear ITS and chloroplast $y c f 1$ sequences more similar to those of other species from the same geographic locality than they do to members of their "own" species. Thus, the question for us is similar to that posed at the beginning of this article: What are the gene tree analyses telling us about the nature of New Zealand alpine Ranunculus species and their evolutionary relationships?

We speculate that these species might be explained by Mallet's (2007) genotypic cluster species concept. That is, while ecologically and morphologically significant traits and their underlying genetic determinants delimit these species, there has, nevertheless, been regional gene flow of neutral genetic markers between sympatric reproductively compatible species. This interpretation would also be consistent with Fisher (1965) in that both interspecific hybridization and divergence are necessary to explain morphological variation within and between the natural populations of the species he described.

We are currently collecting more genetic data to test this hypothesis using the analytical approaches described in the following section. If our hypothesis is correct, it will have implications for using multispecies coalescent tree reconstruction methods with our data. Most notably, if we were to include an increasing number of gene trees for neutral gene loci in a species tree reconstruction for New Zealand alpine Ranunculus given possibly high levels of regional interspecific gene flow, we would not expect reconciliation of discordant gene trees in a way that would represent a meaningful species tree. Given this possible concern, a first step in improving our understanding is to identify the occurrence and extent of past hybridization events involving alpine Ranunculus species. Until recently, and despite a general consensus for the importance of hybridization in plant evolution, quantifying the extent of natural hybridization has been a difficult issue to investigate in a rigorous manner (Arnold, 1997; Brumfield et al., 2008; Joly et al., 2009).

\section{Distinguishing Hybridization from Lineage Sorting}

New methods based on coalescent models have recently been proposed for evaluating introgression (e.g., Joly et al., 2009; Pelser et al., 2010; Gerard et al., 2011; Joly, 2012). They might be applied after first noticing discordance between gene trees, paraphyly, or polyphyly in some reconstructed gene trees but not in others. In the first method, a species tree is inferred from independent gene trees whose genes in the taxa studied are assumed to be unaffected by hybridization. Gene trees are then simulated on this species tree (or posterior distribution for the species tree) assuming a coalescent model that allows for incomplete lineage sorting but not hybridization. The genetic distances between taxa in these simulated gene trees are then compared against genetic distances in the gene trees reconstructed for taxa and molecular markers which are being evaluated for evidence of introgression. Specifically, in instances where non-monophyly is observed in reconstructed gene trees, the question is asked whether genetic distances in the observed gene trees are significantly less than those expected in computer simulations under an assumed coalescent model. If so, then lineage sorting is excluded as an explanation for the 

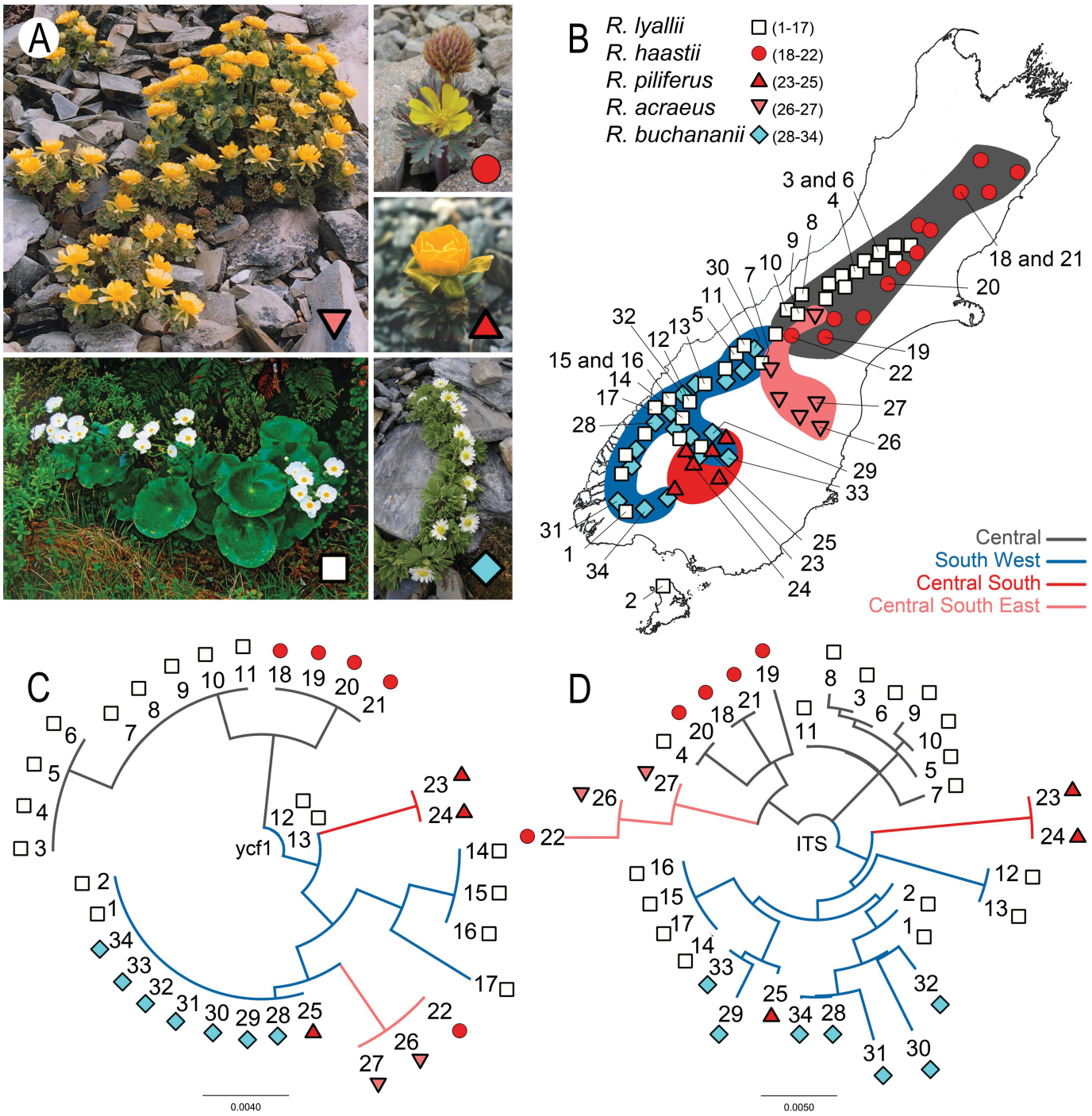

Figure 1. -A. New Zealand alpine Ranunculus species and microhabitats, photo $R$. acraeus: Anne Cartman, photo $R$. buchananii: Bruce van Brunt. - B. Geographic distributions according to Lockhart et al. (2001) and Heenan et al. (2006). —C, D. Accessions sequenced for C and D are numbered: 1, Borland; 2, Mt. Anglem; 3, Edwards; 4, Jagged Stream; 5, Mt. Franklin; 6, Temple Basin; 7, Canyon Creek; 8, Franz Josef; 9, Hooker Valley; 10, Mt. Cook; 11, Mark Range; 12, Mt. Earnslaw; 13, French Ridge; 14, Lake Harris; 15, Mt. Tutoko; 16, Ocean Peak; 17, Mitre Peak; 18, Amuri; 19, Lake Tekapo; 20, Mt. Hutt; 21, Mt. St. Patrick; 22, Ben Ohau; 23, East Dome; 24, Eyre Mts.; 25, Symmetry Peaks; 26, Mt. Pisgah; 27, St. Mary; 28, Homer; 29, Lake Alta; 30, Mt. Brewster; 31, Mt. Burns; 32, Mt. Earnslaw; 33, Skeleton Lake; 34, Takitimu Mts. —C. Neighbor joining tree of chloroplast $y c f 1$. - D Neighbor joining tree of nr ITS sequences. In Lockhart et al. (2001), the $y c f 1$ region was referred to as JSA - the region where $y c f 1$ is located in the chloroplast genome. Trees were constructed with Geneious version $5.6(<\mathrm{http}: / /$ www.geneious.com/ $>$ ).

non-monophyly, and hybridization is inferred. If the distances are not significantly less, then incomplete lineage sorting remains a possible explanation for the data. The approach suggested by Pelser et al. (2010) is similar, but these authors invert the argument. Certain genetic distances between different species are only expected given certain ancestral population sizes. If estimates of these population sizes are far greater than is reasonable, then incomplete lineage sorting can also be rejected. In Meng and Kubatko (2009) and Gerard et al. (2011), an estimate of the extent of introgression in an a priori specified taxon is made by comparing observed gene trees with trees simulated on the parental trees (or "principal" trees 
as they have been called in Holland et al., 2008) embedded within a rooted reticulate phylogenetic network.

All of the above methods require that the reference species tree (or posterior distribution of species trees: Joly, 2012) is reliably inferred and not itself impacted by hybridization. While this is a limitation (and potentially can introduce circularity), in practice it means that implementations of the test need to be conservative, and simulations might not be able to be conducted using all species belonging to a group. When the test of Joly et al. (2009) was proposed, we illustrated the test using a data set similar to that shown in Figure 1. However, at $P=0.05$ level we could not reject lineage sorting as an explanation for the observed patterns of paraphyly. We felt this might be the result of the relatively short concatenated chloroplast sequences used in the analyses. We have now sequenced complete chloroplast genomes for some of our alpine Ranunculus species (unpublished) and also made progress in developing EST libraries for alpine Ranunculus species using Illumina sequencing protocols (Atherton et al., 2010; Gruenheit et al., 2012). However, the analyses from this further work are not complete at the time of writing. The hope is that, given these additional data, we will soon be in a better position to understand the meaning of the paraphyletic gene trees observed in phylogenetic reconstructions of our species (Fig. 1). That is, we look to these data to help us determine what gene trees are telling us about the nature of our species and their evolutionary relationships.

\section{Genome Science and the Nature of Species}

Recent studies have provided an overwhelming number of species concepts (see $<$ http://www.ucl.ac. uk/taxome/jim/Sp/species.pdf $>$ ) and a sense that authors are often referring to different entities when discussing species in their favorite group of organisms. Introgression and horizontal gene transfer between species have evidently occurred in many groups of organisms-plants, animals, and microbes (Dagan et al., 2008; Mallet, 2008b). These inferences have been made as a result of the increasing number of genetic markers that have become available for non-model organisms. With methods such as those described above, the power for detection of hybrids increases greatly (Joly et al., 2009; Gerard et al., 2011). It is exciting to think that very soon, with highthroughput sequencing of genomes and transcriptomes, we will have our best glimpse yet of the genetic distinctiveness of species, their evolutionary transience, and complexity of relationships.

\section{Conclusions}

The significance of paraphyletic taxa in our phylogenetic reconstructions will become clear once we have a better understanding of the nature of species and their evolutionary relationship with other species. If interspecific gene flow is limited, paraphyletic gene trees are neither unexpected nor problematic for species tree reconstruction methods (Schmidt-Lebuhn, 2011). However, this is not the case if hybridization is more pervasive. The concept of "species" used in species tree methods is one that fits uncomfortably with the suggested complex nature of many plant species, including Ranunculus (Hörandl \& Emadzade, 2012). In such cases, there remains uncertainty over the interpretation of paraphyletic gene trees and whether or not discordant gene trees indicate complex relationships among species or incomplete lineage sorting characteristic of species radiations (Degnan \& Rosenberg, 2009). Analytical approaches such as those outlined above provide new tools to better evaluate these trees as well as the extent and importance of hybridization in nature. If such study shows that hybridization is as significant as some authors have suggested, then there will be increased impetus to develop more appropriate coalescent models for species trees methodology (as already suggested: Brumfield et al., 2008). Alternatively, such a finding might stimulate the further development of approaches for reconstructing species relationships that are model free and based on criteria such as data partition concordance (e.g., see Larget et al., 2010) and/or those that get away entirely from Darwin's sticklike figure and consider heuristic solutions to the problem of reconstructing reticulate hybridization networks (e.g., Huson et al., 2005; as used in Pirie et al., 2009). Ultimately, the aim will be to better understand and describe the plant biodiversity in front of us, and progress will only come with improved understanding of the genetic data at hand. Developing this understanding will be an important contribution to the debate over whether or not to recognize paraphyletic species.

\section{Literature Cited}

Arnold, M. L. 1997. Natural Hybridization and Evolution. Oxford University Press, Oxford.

Atherton, R. A., B. J. McComish, L. D. Shepherd, L. Berry \& P. J. Lockhart. 2010. Chloroplast isolation and high throughput DNA sequencing for studies in molecular ecology and evolution. BMC Pl. Meth. 6: 22.

Beerli, P. \& J. Felsenstein. 2001. Maximum likelihood estimation of a migration matrix and effective population sizes in $\mathrm{n}$ subpopulations by using a coalescent approach. Proc. Natl. Acad. Sci. U.S.A. 98(8): 4563-4568. 
Brooks, J. L. 1984. Just Before the Origin: Alfred Russel Wallace's Theory of Evolution. Columbia University Press, New York.

Brumfield, R. T., L. Liu, D. E. Lum \& S. V. Edwards. 2008. Comparison of species tree methods for reconstructing the phylogeny of bearded makins (Aves: Pipridae, Manacu) from multilocus sequence data. Syst. Biol. 57(5): 719-731.

Bryant, D., R. Bouckaert, J. Felsenstein \& N. A. Rosenberg. 2012. Inferring species trees directly from biallelic genetic markers: Bypassing gene trees in a full coalescent. Molec. Biol. Evol. 29(9): 1917-1932.

Chung, Y. \& C. Ané. 2011. Comparing two Bayesian methods for gene tree/species tree reconstruction: Simulations with incomplete lineage sorting and horizontal gene transfer. Syst. Biol. 60(3): 261-275.

Cockayne, L. \& H. H. Allan. 1926. The naming of wild hybrid swarms. Nature 118: 623-624.

Coyne, J. A. \& H. A. Orr. 2004. Speciation. Sinauer Associates, Sunderland, Massachusetts.

Cranston, K. A., B. Hurwitz, D. Ware, L. Stein \& R. A. Wing. 2009. Species trees from highly incongruent trees in rice. Syst. Biol. 58(5): 489-500.

Dagan, T., Y. Artzy-Randrup \& W. Martin. 2008. Modular networks and cumulative impact of lateral transfer in prokaryote genome evolution. Proc. Natl. Acad. Sci. U.S.A. 105: 10,039-10,044.

Darwin, C. 1859. On the Origin of Species. John Murray, London.

Degnan, J. H. \& L. Salter. 2005. Gene tree distributions under the coalescent process. Evolution 59: 24-37.

Degnan, J. H. \& N. A. Rosenberg. 2009. Gene tree discordance, phylogenetic inference and the multispecies coalescent. Trends Ecol. Evol. 24: 332-340.

Donoghue, M. J. 1985. A critique of the biological species concept and recommendations for a phylogenetic alternative. Bryologist 88: 172-181.

Ehrendorfer, F. 1959. Differentiation-hybridization cycles and polyploidy in Achillea. Cold Spring Harbor Symp. Quant. Biol. 24: 141-152.

Fan, H. H. \& L. S. Kubatko. 2011. Estimating species trees using approximate Bayesian computation. Molec. Phylogen. Evol. 59: 354-363.

Fisher, F. 1965. The Alpine Ranunculi of New Zealand. DSIR Publishing, Wellington.

Fujita, M. K., A. D. Leache, F. T. Burbrink, J. A. McGuire \& C. Moritz. 2012. Coalescent-based species delimitation in an integrative taxonomy. Trends Ecol. Evol. 27(9): 480-488.

Gerard, D., H. L. Gibbs \& L. Kubatko. 2011. Estimating hybridization in the presence of coalescence using phylogenetic intraspecific sampling. BMC Evol. Biol. 11: 291.

Gruenheit, N., O. Deusch, C. Esser, M. Becker, C. Voelckel \& P. J. Lockhart. 2012. Cutoffs and k-mers: Implications from a transcriptome study in allopolyploid plants. BMC Genomics 13: 92.

Heenan, P., P. J. Lockhart, N. Kirkam \& D. Havell. 2006. Relationships in the alpine Ranunculus haastii (Ranunculaceae) complex and recognition of $R$. piliferus and $R$. acraeus from southern New Zealand. New Zealand J. Bot. 44: 425-441.

Heled, J. \& A. J. Drummond. 2010. Bayesian inference of species trees from multilocus data. Molec. Biol. Evol. 27: $570-580$.
Hendy, M. D. \& D. Penny. 1989. A framework for the quantitative study of evolutionary trees. Syst. Zool. 38: 297-309.

Herder, F., A. W. Nolte, J. Pfaender, J. Schwarzer, R. K. Hadiaty \& U. K. Schliewen. 2006. Adaptive radiation and hybridization in Wallace's Dreamponds: Evidence from sailfin silversides in the Malili Lakes of Sulawesi. Proc. Roy. Soc. London Ser. B, Biol. Sci. 273: 2209 2217.

Hoffman, A. A. \& C. M. Sgro. 2011. Climate change and evolutionary adaptation. Nature 470: 479-485.

Holland, B. R., S. Benthin, P. J. Lockhart, V. Moulton \& K. T. Huber. 2008. Using supernetworks to distinguish hybridization from lineage-sorting. BMC Evol. Biol. 8: 202.

Hörandl, E. \& T. F. Stuessy. 2010. Paraphyletic groups as natural units of biological classification. Taxon 59: 16411653.

Hörandl, E. \& K. Emadzade. 2012. Evolutionary classification: A case study on the diverse plant genus Ranunculus L. (Ranunculcaeae). Perspect. Pl. Ecol. Evol. Syst. 14: 310-324.

Huson, D., T. Kloepper, P. J. Lockhart \& M. A. Steel. 2005. Reconstruction of reticulate networks from gene trees. Pp. 233-249 in Proceedings of the Ninth International Conference in Computational Molecular Biology (RECOMB).

Joly, S. 2012. JML: Testing hybridization from species trees. Molec. Ecol. Resources 12: 179-184.

Joly, S., P. A. McLenachan \& P. J. Lockhart. 2009. A statistical approach for distinguishing hybridization and incomplete lineage sorting. Amer. Naturalist 174: E5470.

Knowles, L. L. 2009. Estimating species trees: Methods of phylogenetic analysis when there is incongruence across genes. Syst. Biol. 58: 463-467.

Kubatko, L. S., B. C. Carstens \& L. L. Knowles. 2009. STEM: Species tree estimation using maximum likelihood for gene trees under coalescence. Bioinformatics 25 : 971-973.

Larget, B. R., S. K. Kotha, C. N. Dewey \& C. Ané. 2010. BUCKy: Gene tree/species tree reconciliation with Bayesian concordance analysis. Bioinformatics 26(22): 2910-2911.

Linder, H. P. 2008. Plant species radiations: Where, when, why? Philos. Trans., Ser. B 363: 3097-3105.

Linnaeus, C. 1736. Fundamenta Botanica. Solomon Schouten, Amsterdam.

Liu, L., L. Yu, L. Kubatko, D. K. Pearl \& S. V. Edwards. 2009. Coalescent methods for estimating phylogenetic trees. Molec. Phylogen. Evol. 53: 320-328.

Lockhart, P. J., P. A. Mclenachan, D. Havell, D. Glenny, D. Huson \& U. Jensen. 2001. Phylogeny, radiation, and transoceanic dispersal of New Zealand Alpine buttercups: Molecular evidence under split decomposition. Ann. Missouri Bot. Gard. 88: 458-477.

Mallet, J. 2007. Hybrid speciation. Nature 446: 279-283.

Mallet, J. 2008a. A Century of Evolution: Ernst Mayr (1904-2005). Mayr's view of Darwin: Was Darwin wrong about speciation? Biol. J. Linn. Soc. 95: 3-16.

Mallet, J. 2008b. Hybridization, ecological races and the nature of species: Empirical evidence for the ease of speciation. Philos. Trans., Ser. B 363: 2971-2986.

Martin, W., O. Deusch, N. Stawski, N. Gruenheit \& V. Goremykin. 2005. Chloroplast genome phylogenetics: 
Why we need independent approaches to plant molecular evolution. Trends Pl. Sci. 10: 203-205.

Mayr, E. 1963. Animal Species and Evolution. Harvard University Press, Cambridge.

Mayr, E. 1968. Illiger and the biological species concept. J. Hist. Biol. 1: 163-178.

Meng, C. \& L. S. Kubatko. 2009. Detecting hybrid speciation in the presence of incomplete lineage sorting using gene tree incongruence: A model. Theor. Popul. Biol. 75: 35-45.

Pelser, P. B., A. H. Kennedy, E. J. Tepe, J. B. Shidler, B. Nordenstam, J. W. Kadereit \& L. E. Watson. 2010. Patterns and causes of incongruence between plastid and nuclear Senecioneae (Asteraceae) phylogenies. Amer. J. Bot. 97: 856-873.

Pennington, R. T., M. Lavin, T. Särkinen, G. P. Lewis, B. B. Klitgaard \& C. E. Hughes. 2010. Contrasting plant diversification histories within the Andean biodiversity hotspot. Proc. Natl. Acad. Sci. U.S.A. 107: 13,78313,787 .

Penny, D. 2011. Darwin's theory of descent with modification versus the biblical tree of life. <http://www. plosbiology.org/article/info\%3Adoi\%2F $10.1371 \%$ 2Fjournal.pbio.1001096 $>$, accessed 27 November 2012.

Pirie, M. D., A. M Humphreys, N. P. Barker \& H. P. Linder. 2009. Reticulation, data combination, and inferring evolutionary history: An example from Danthonioideae (Poaceae). Syst. Biol. 58(6): 612-628.

Raven, C. E. 1986. John Ray, Naturalist: His Life and Works, 2nd ed. Cambridge University Press, Cambridge.

Rieseberg, L. H. 1997. Hybrid origins of plant species. Annual Rev. Ecol. Syst. 28: 359-389.

Rosenberg, N. A. 2007. Statistical test for taxonomic distinctiveness from observations of monophyly. Evolution 61: 317-323.
Schmidt-Lebuhn, A. N. 2011. Cladistics fallacies and false premises-A critical assessment of the arguments for the recognition of paraphyletic taxa in botany. Cladistics 27: $1-14$.

Shavit, L., D. Penny, M. D. Hendy \& B. R. Holland. 2007. The problem of rooting rapid radiations. Molec. Biol. Evol. 24: 2400-2411.

Soltis, P. S. \& D. E. Soltis. 2009. The role of hybridization in plant speciation. Annual Rev. Pl. Biol. 60: 561-588. Stauffer, R. C. 1975. Charles Darwin's Natural Selection; Being the Second Part of His Big Species Book Written from 1836 to 1858. Cambridge University Press, Cambridge.

Stebbins, G. L. 1959. The role of hybridization in evolution. Proc. Amer. Philos. Soc. 103: 231-251.

Stemshorn, K. C., F. A. Reed, A. W. Nolte \& D. Tautz. 2011. Rapid formation of distinct hybrid lineages after secondary contact of two fish species (Cottus sp.). Molec. Ecol. 20: 1475-1491.

Valente, L. M., V. Savolainen, P. Vargas, L. M. Valente, V. Savolainen \& P. Vargas. 2010. Unparalleled rates of species diversification in Europe. Proc. Roy. Soc. London, Ser. B, Biol. Sci. 277: 1489-1496.

Wallace, A. R. 1855. On the law which has regulated the introduction of new species. Ann. Mag. Nat. Hist. 16: 184-196.

Webb, C. J., W. R. Sykes \& P. J. Garnock-Jones. 1988. Flora of New Zealand, Vol. 4. Landcare Research, Lincoln, New Zealand.

Wiley, E. O. 2009. Patrocladistics, nothing new. Taxon 58: 2-6.

Winkworth, R. C., S. J. Wagstaff, D. Glenny \& P. J. Lockhart. 2005. Evolution of the New Zealand mountain flora: Origins, diversification and dispersal. Organisms Diversity Evol. 5: 237-247. 